\title{
Simultaneous Resection of Primary Colorectal Cancer and Synchronous Liver Metastases: Contemporary Practice, Evidence and Knowledge Gaps
}

\author{
Dyre Kleive · Eline Aas · Jon-Helge Angelsen · Erling A. Bringeland • \\ Arild Nesbakken • Linn S. Nymo • Johannes K. Schultz • \\ Kjetil Søreide $\cdot$ Sheraz Yaqub iD
}

Received: February 3, 2021 / Accepted: March 6, 2021 / Published online: March 23, 2021

(c) The Author(s) 2021

\begin{abstract}
The timing of surgical resection of synchronous liver metastases from colorectal cancer has been debated for decades. Several strategies have been proposed, but high-level evidence remains scarce. Simultaneous resection of the primary tumour and liver metastases has been described in numerous retrospective audits and metaanalyses. The potential benefits of simultaneous resections are the eradication of the tumour
\end{abstract}

D. Kleive $\cdot$ S. Yaqub $(\bowtie)$

Department of Hepatobiliary and Pancreatic Surgery, Oslo University Hospital, Oslo, Norway e-mail: shya@ous-hf.no

E. Aas

Department of Health Management and Health Economics (HELED), Institute of Health and Society, University of Oslo, Oslo, Norway

E. Aas

Health Services Research Unit, Akershus University Hospital, Lørenskog, Norway

J.-H. Angelsen

Department of Gastrointestinal Surgery, Haukeland University Hospital, Bergen, Norway

E. A. Bringeland

Department of Gastrointestinal Surgery, St. Olavs University Hospital, Trondheim, Norway

\section{A. Nesbakken}

Department of Gastrointestinal Surgery, Oslo

University Hospital, Oslo, Norway burden in one procedure, overall shorter procedure time, reduced hospital stay with the likely benefits on quality of life and an expected reduction in the use of health care services compared to staged procedures. However, concerns about accumulating complications and oncological outcomes remain and the optimal selection criteria for whom simultaneous resections are beneficial remains undetermined. Based on the current level of evidence, simultaneous resection should be restricted to patients with a limited liver tumour burden. More high-level evidence studies are needed to

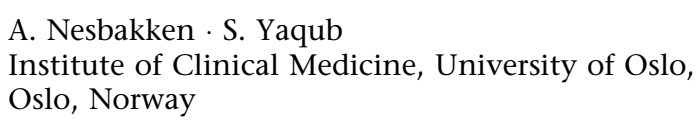

\section{S. Nymo}

Department of Gastrointestinal Surgery, University Hospital of North Norway, Tromsø, Norway

\section{J. K. Schultz}

Department of Gastrointestinal Surgery, Akershus

University Hospital, Lørenskog, Norway

K. Søreide

Department of Gastrointestinal Surgery, Stavanger University Hospital, Stavanger, Norway

K. Søreide

Department of Clinical Medicine, University of Bergen, Bergen, Norway 
evaluate the quality of life, complication burden, oncological outcomes, as well as overall health care implications for simultaneous resections.

Keywords: Colorectal cancer; Colorectal resection; Liver resection; Simultaneous resection; Surgical oncology; Surgical outcomes; Synchronous liver metastasis

\section{Key Summary Points}

High-level evidence in simultaneous resection of colorectal cancer and colorectal liver metastasis remains scarce.

Simultaneous resections may be considered in patients with good performance status and limited liver tumour burden.

Simultaneous resections should be avoided when requiring major liver resection and major colorectal resection.

Treatment strategies should be made by a multidisciplinary team.

Simultaneous resections should be performed as part of a clinical trial.

\section{DIGITAL FEATURES}

This article is published with digital features, including a summary slide, to facilitate understanding of the article. To view digital features for this article, go to https://doi.org/10.6084/ m9.figshare.14170694.

\section{INTRODUCTION}

The optimal timing of surgical resection of synchronous liver metastases from colorectal cancer is not well defined. Traditionally, resection of the primary tumour and the liver metastases is done at separate admissions, with

a period of recovery allowed between the two procedures. This could be done either as resection of the liver metastases before the colorectal tumour or in the reversed order. Simultaneous resection of both the colorectal cancer and the liver metastases has gained popularity due to several appealing factors. The tumour burden can be eradicated in one procedure, which intuitively could have a positive impact on quality of life. One versus two procedures is likely to reduce the overall burden on health care institutions and lower hospital costs with a reduced admission rate. However, an increase in overall and procedure-specific post-operative morbidity after simultaneous resection have been reported $[1,2]$. Conversely, the traditional approach with staged resections may also be argued. An interval between the resection of the primary tumour and the resection of the liver metastases allows a test of time to evaluate the individual tumour biology of the metastatic disease. The consequence of a staged procedure might be progression of the liver metastases to such an extent that they are no longer considered resectable. While tumour progression in the perioperative "window" between the two procedures may be unfavourable, it may spare the patient of a potentially futile liver resection that would otherwise have had a limited effect on cancer biology and the long-term survival.

There is currently a lack of high-level evidence to accurately determine the role of simultaneous resection of colorectal cancer with liver metastases. Previous reports are generally biased by the fact that patients selected to simultaneous versus non-simultaneous surgery differ in many aspects concerning both the primary tumour and the manifestation of the liver metastases. Furthermore, recent investigations reveal considerable differences in the perioperative management of synchronous colorectal liver metastases, with no clear surgical outcome or survival advantage towards any approach, being liver-first, colorectal-first or simultaneous resection $[3,4]$. This invited opinion article aims to address the current level of evidence concerning simultaneous resection of primary colorectal cancer and synchronous liver metastases. We propose selection criteria, based on available data, for whom a 
simultaneous procedure is likely to be beneficial. This article is based on previously conducted studies and does not contain any new studies with human participants or animals performed by any of the authors.

\section{CURRENT EVIDENCE}

Throughout the last two decades, numerous retrospective studies have compared simultaneous versus staged resection for synchronous colorectal liver metastases. The findings have been reported in several reviews and metaanalyses (Table 1) [3, 5-10]. However, the results are somewhat difficult to interpret due to inherent selection bias [11]. Generally, the outcomes from these studies show equal shortand long-term results between simultaneous and staged approaches, besides shorter hospital stay for patients with simultaneous resection. Patients with bilobar liver metastases and in need for major hepatectomy have traditionally been scheduled for staged surgery. Also, most of the register-based studies do not account for patients with an initial intent for a staged strategy, but in whom a proportion of patients never reached hepatectomy due to disease progression. Indeed, some studies report that between 16 and $35 \%$ of patients with an either liver-first or primary tumour-first strategy do not reach the second operation, likely due to disease progression or complications from the first procedure [12-14]. Hence, in the abovementioned systematic reviews and meta-analysis, there is an inherent selection bias in favour of patients completing a staged approach, as they likely harbour a favourable tumour biology in order to reach the second procedure. Also, for patients receiving a simultaneous resection, there is a selection bias in favour of a limited liver tumour burden.

A recent population-based cohort study confirmed an increased tendency towards simultaneous resection and a wide variation in surgical approach according to hospital trust of diagnosis in the UK [4]. Survival analysis on propensity score-matched groups showed no difference in 4-year survival between the primary tumour-first and simultaneous cohort.
Interestingly, the presence of a hepatobiliary surgical team on site appeared to have an impact on decision-making, as patients diagnosed at hospital trusts with such service were more likely to undergo a simultaneous or liverfirst approach.

Recently, a randomized controlled trial addressed the question of whether synchronous colorectal liver metastases should be resected simultaneously with the primary cancer or delayed [15]. There are several interesting findings and lessons to be learned from this trial. First, there was no difference in major complications comparing synchronous to delayed resection. Second, although 10 centres were involved in the study, the overall recruitment time was a decade. Even this was not enough to reach the calculated sample size (estimated 222 patients), in spite of rather broad inclusion criteria, accepting major hepatectomy, patients with bilobar liver metastases and patients with rectal cancer. According to the authors, this was mainly explained by the fact that (i) colorectal cancer with initially resectable synchronous liver metastases remains a rare situation, (ii) centres involved in the study often had patients referred with poor overall status and initially non-resectable synchronous liver metastases and (iii) the majority of patients were referred after the primary tumour had been resected. The first point is debatable, as data for colorectal liver metastases reflect a highly divergent attitude among surgeons towards what is considered 'resectable' disease [16]. Furthermore, novel techniques have been developed in order to increase resectability [17]. The latter two points reflect challenges in logistical and hospital organizational structure rather than the lack of patients eligible for the procedures. Not all colorectal units have hepatobiliary surgeons available and vice versa, which should be taken into account when planning for simultaneous resection. Hence, this also reflects the third point, that referral between pure colorectal units and hepatobiliary units is required if patients are not discussed at the same multidisciplinary team (MDT) meeting. Even at institutions with both services available, most MDTs are run separately, thus representing a barrier in planning simultaneous resection if 
Table 1 Recent reviews and meta-analyses of different treatment strategies for colorectal cancer with liver metastases

\begin{tabular}{|c|c|c|c|c|c|}
\hline $\begin{array}{l}\text { Author, } \\
\text { year }\end{array}$ & $\begin{array}{l}\text { Number of } \\
\text { patients/ } \\
\text { studies } \\
\text { included }\end{array}$ & $\begin{array}{l}\text { Groups } \\
\text { compared }\end{array}$ & $\begin{array}{l}\text { Primary } \\
\text { outcome }\end{array}$ & Results & Comments \\
\hline $\begin{array}{l}\text { Hillingsø } \\
\text { et al. } \\
2009[8]\end{array}$ & $\begin{array}{l}\text { Not } \\
\text { available/ } \\
16 \text { studies }\end{array}$ & $\begin{array}{l}\text { Simultaneous vs } \\
\text { delayed }\end{array}$ & $\begin{array}{l}\text { Length of stay, } \\
\text { morbidity, } \\
\text { mortality, } \\
\text { OS }\end{array}$ & $\begin{array}{l}\text { Lower morbidity for } \\
\text { simultaneous resection, } \\
\text { lower mortality for } \\
\text { delayed resection, similar } \\
\text { OS }\end{array}$ & $\begin{array}{l}\text { Systematic review without } \\
\text { meta-analysis. } \\
\text { Simultaneous resection } \\
\text { performed for patients } \\
\text { with fewer, unilobar } \\
\text { metastases and right-sided } \\
\text { colon cancer. Surgery for } \\
\text { left-sided colon cancer and } \\
\text { major hepatectomy were } \\
\text { mainly staged procedures }\end{array}$ \\
\hline $\begin{array}{l}\text { Slesser } \\
\text { et al. } \\
2013 \text { [9] }\end{array}$ & $\begin{array}{l}3159 \\
\text { patients/ } \\
24 \text { studies }\end{array}$ & $\begin{array}{l}\text { Simultaneous vs } \\
\text { delayed }\end{array}$ & $\begin{array}{l}\text { Length of stay, } \\
\text { 30-day } \\
\text { mortality } \\
\text { and } \\
\text { morbidity, } \\
\text { OS and } \\
\text { DFS }\end{array}$ & $\begin{array}{l}\text { No difference in blood loss } \\
\text { or duration of surgery. No } \\
\text { differences in morbidity, } \\
\text { OS or DFS. Reduction of } \\
5.6 \text { days in hospital stay } \\
\text { for simultaneous resection }\end{array}$ & $\begin{array}{l}\text { More major hepatectomy } \\
\text { and patients with bilobar } \\
\text { distribution of metastases } \\
\text { for patients undergoing } \\
\text { delayed resection }\end{array}$ \\
\hline $\begin{array}{l}\text { Kelly et al. } \\
2013[3]\end{array}$ & $\begin{array}{l}3605 \\
\text { patients/ } \\
18 \text { studies }\end{array}$ & $\begin{array}{l}\text { Liver first, } \\
\text { simultaneous } \\
\text { and colon } \\
\text { first }\end{array}$ & $\begin{array}{l}\text { 5-year OS, } \\
\text { 30-day } \\
\text { mortality, } \\
\text { morbidity }\end{array}$ & $\begin{array}{l}\text { No differences in primary } \\
\text { outcome among the three } \\
\text { groups }\end{array}$ & $\begin{array}{l}\text { No clear statistical surgical } \\
\text { outcome or survival } \\
\text { advantage towards any } \\
\text { approach }\end{array}$ \\
\hline $\begin{array}{l}\text { Yin et al. } \\
2013 \\
{[10]}\end{array}$ & $\begin{array}{l}2880 \\
\text { patients/ } \\
17 \text { studies }\end{array}$ & $\begin{array}{l}\text { Simultaneous vs } \\
\text { delayed }\end{array}$ & $\begin{array}{l}\text { Morbidity, } \\
\text { mortality, } \\
\text { OS and } \\
\text { DFS }\end{array}$ & $\begin{array}{l}\text { No difference in primary } \\
\text { outcome }\end{array}$ & \\
\hline $\begin{array}{l}\text { Feng et al., } \\
2014 \text { [6] }\end{array}$ & $\begin{array}{l}22 \text { studies/ } \\
4494 \\
\text { patients }\end{array}$ & $\begin{array}{l}\text { Simultaneous vs } \\
\text { delayed }\end{array}$ & $\begin{array}{l}\text { Mortality, } \\
\text { morbidity, } \\
\text { OS, DFS }\end{array}$ & $\begin{array}{l}\text { Similar morbidity, mortality, } \\
\text { OS and DFS }\end{array}$ & \\
\hline $\begin{array}{l}\text { Baltatzis } \\
\text { et al. } \\
2016[5]\end{array}$ & $\begin{array}{l}1203 \\
\text { patients/ } \\
3 \text { studies }\end{array}$ & $\begin{array}{l}\text { Liver first, } \\
\text { simultaneous } \\
\text { and colon } \\
\text { first }\end{array}$ & $\begin{array}{l}\text { Morbidity, } \\
\text { mortality, } \\
\text { 5-year OS }\end{array}$ & $\begin{array}{l}\text { Low treatment mortality, } \\
\text { similar survival among the } \\
\text { groups compared }\end{array}$ & \\
\hline
\end{tabular}


Table 1 continued

\begin{tabular}{|c|c|c|c|c|c|}
\hline $\begin{array}{l}\begin{array}{l}\text { Author, } \\
\text { year }\end{array}\end{array}$ & $\begin{array}{l}\text { Number of } \\
\text { patients/ } \\
\text { studies } \\
\text { included }\end{array}$ & $\begin{array}{l}\text { Groups } \\
\text { compared }\end{array}$ & $\begin{array}{l}\text { Primary } \\
\text { outcome }\end{array}$ & Results & Comments \\
\hline $\begin{array}{l}\text { Gavriilidis } \\
\text { et al. } \\
2018 \text { [7] }\end{array}$ & $\begin{array}{l}30 \text { studies/ } \\
5300 \\
\text { patients }\end{array}$ & $\begin{array}{l}\text { Simultaneous vs } \\
\text { delayed }\end{array}$ & $\begin{array}{l}\text { OS, safety and } \\
\text { efficacy }\end{array}$ & $\begin{array}{l}\text { Similar long-term OS, no } \\
\text { difference in parameters } \\
\text { relating to safety and } \\
\text { efficacy }\end{array}$ & $\begin{array}{l}\text { An average of } 6 \text { days shorter } \\
\text { length of stay for } \\
\text { simultaneous } \\
\text { resection. More patients } \\
\text { with bilobar disease and } \\
\text { major hepatectomy in the } \\
\text { delayed surgery group }\end{array}$ \\
\hline
\end{tabular}

$O S$ overall survival, $D F S$ disease-free survival

the surgeons are biased towards one strategy over another. Of note, payer systems vary across health care providers, and the financial incentives for any approach (primary first, liver first or simultaneous) have an impact on decisions in some countries where billing for service is implied.

The overall complication rate in this solitary RCT on the subject, mirrors the inclusion criteria, in that almost 1 out of 2 patients in both groups had a complication grade III or IV according to the Clavien-Dindo classification [15]. Again, a reduction of hospital stay was proven for patients with simultaneous surgery. Survival analysis was not conducted according to intention-to-treat principles. As the trial was underpowered to answer the primary outcome measure, the question still stands: for whom is simultaneous resection beneficial?

\section{PRINCIPLES OF PATIENT SELECTION}

As there is evidence of a negative impact from post-operative complications on long-term outcomes after liver surgery for colorectal liver metastases, the magnitude of surgical resection should be better stratified to guide patient management decisions $[18,19]$. Feasibility reports on major hepatectomy with concomitant colectomy exist, but this procedure is likely to be reserved for highly selected patients and experienced surgeons [20]. In 2015, a consensus statement was published, recommending that simultaneous resection be discouraged when the hepatectomy would be major (involving three or more adjacent liver segments) or when complex rectal surgery was to be performed, due to significantly higher post-operative mortality and morbidity [21]. Recent evidence supports this recommendation. Schubert and co-authors stratified synchronous hepatic and colorectal resections, finding increased morbidity and mortality for patients undergoing high-risk colorectal resections and major hepatectomy [22]. Driedger and co-authors recently published a 17-year experience and defined major hepatectomy as hemihepatectomy and trisectionectomy, and major colectomy as left colectomy with proximal diversion, total abdominal colectomy, total abdominal proctocolectomy and abdominoperineal resection [19]. Combining a major liver with major colorectal resection was associated with a significant increase in major morbidity and 90-day mortality. Also, more than one-third of these patients were prevented from receiving adjuvant chemotherapy secondary to post-operative morbidity. These findings are in line with a recent 
investigation on surgeons' barriers in performing simultaneous resection, with low support for cases involving major hepatectomy [23].

Lastly, numerous prognostic indicators are available for patients with colorectal cancer and liver metastases, such as sidedness of primary tumour, metastatic tumour burden (number and size of largest lesion), and number of involved lymph nodes of resected primary and mutational status [24-28]. However, in the simultaneous setting, a test of time is not possible, and unsurprisingly, a meta-analysis by Slesser and co-authors found no difference in overall or disease-free survival even if the delayed surgery group had a significantly higher proportion of major liver resections, patients with bilobar distribution and an overall larger metastatic tumour size [9]. Hence, until further evidence on potential oncological benefits is available, simultaneous surgery should be offered to appropriate patients at specialized centres regardless of underlying biological features of the metastatic colorectal cancer.

In line with the above-mentioned publications and consensus statements, we believe that simultaneous resection should be considered for patients with localized colorectal cancer and with limited metastatic tumour burden in the liver, both in terms of number of lesions and required resections and the location of the liver metastases. We recommend avoiding resection of more than two adjacent segments (i.e. hemihepatectomy) for anatomical liver resections and preferably four or fewer metastases for non-anatomical liver resections (Table 2). The combination of ablation therapy (radiofrequency/microwave ablation) and hepatic resection has been proven a valid and safe modality without increased perioperative morbidity or mortality compared to resection alone [29]. In order to avoid accumulation of complications and thereby hamper the possibility of adjuvant chemotherapy, we believe simultaneous surgery should be restricted to patients with good performance status and not in the setting of acute bowel obstruction. Furthermore, as a higher complication profile might be the case for patients undergoing rectal cancer surgery, simultaneous resection for these patients should be considered only in selected cases. For patients with non-resectable lung metastases and/or extrahepatic disease, simultaneous resection should be avoided. This is in line with the current National Comprehensive Cancer Network (NCCN) guidelines stating that primary tumour and resectable metastatic disease can be resected in one operation or staged, depending on the complexity of the hepatectomy or colectomy, comorbid diseases, surgical exposure and surgeon expertise [30].

\section{SURGICAL TECHNIQUE IN SIMULTANEOUS RESECTION}

A laparoscopic or open approach for either part of the procedures should be at the surgeon's discretion. There is reason to believe that minimally invasive techniques for both the liver and the colorectal part of the procedure are associated with beneficial short-term outcomes $[31,32]$. As for laparoscopic liver surgery, there is evidence to support equal oncological outcomes for laparoscopic and open colon surgery $[33,34]$. The colorectal surgery should be performed by a trained colorectal surgeon and the liver surgery by a trained hepatobiliary surgeon. There is no evidence that higher volume per surgical unit has a relationship with perioperative outcome regarding the liver resection part of the procedure [35], so specific volume requirements should not be necessary. In colorectal cancer surgery, however, high volume by surgeon and high volume by hospital have been associated with better outcomes, although the optimal threshold for a minimum number of procedures is yet to be identified [36]. Lastly, the optimal surgical treatment sequence in simultaneous resection remains debatable. A liver-first approach is reasonable, given the possible need for a Pringle manoeuvre with a subsequent venous stasis that could potentially harm a bowel anastomosis. Also, a liver-first strategy necessitates a low central venous pressure during the parenchymal transection phase. Finally, any unforeseen event during the liver resection part (major bleed or bile leak) should be considered as a contraindication from continuing with the bowel resection. 
Table 2 Proposed selection criteria in favour of simultaneous resection (green box) or staged resection (red box) of primary colorectal cancer with liver metastases

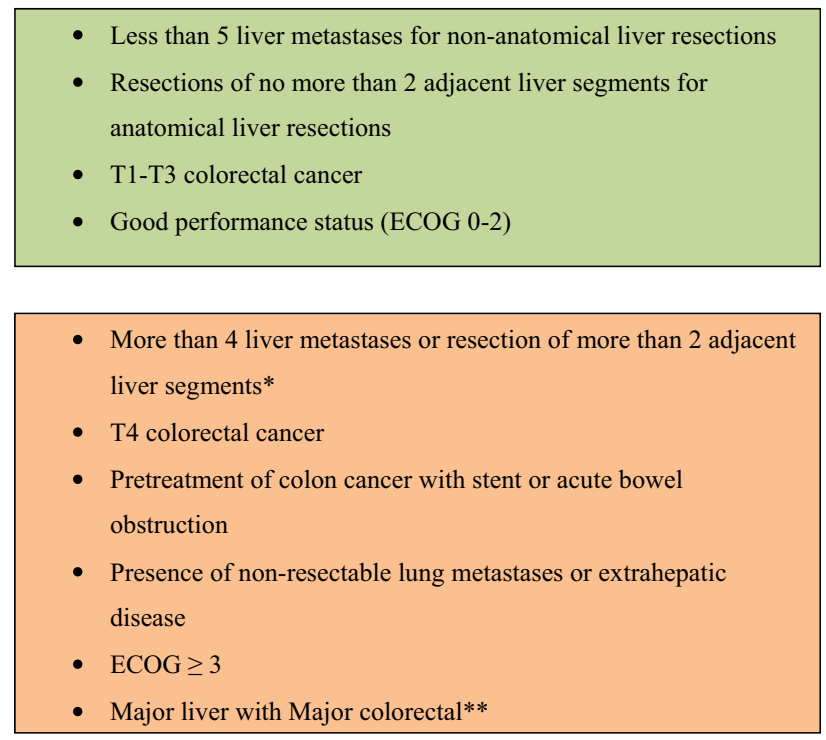

${ }^{*}$ In the case of excessive bleeding, preoperatively under-staged tumour burden, prolonged operative time, unstable patient or any other reason to fear increased complication of either the liver-part or colorectal-part of the procedure, we recommend avoiding simultaneous surgery

** Major liver: hemi-hepatectomy or trisectionectomy. Major colorectal: left colectomy with proximal diversion, total abdominal colectomy, total abdominal proctocolectomy and abdominoperineal resection as defined by Driedger and coauthors [19]

\section{LOGISTICAL CONSIDERATIONS IN SIMULTANEOUS RESECTION}

Simultaneous resection carries some logistical challenges that have to be solved: (i) both the colorectal and hepatobiliary surgeon need to attend the MDT meeting, (ii) both surgeons have to perform their part of the surgery, (iii) an anaesthesiologist familiar with low central venous pressure during the liver parenchymal transection phase will have to be involved, and (iv) both surgeons will have to do the immediate post-operative follow-up in order to catch any sign of complications. Furthermore, adequate interventional radiology resources and inpatient facilities are mandatory in order to avoid failure to rescue. In case patients require neoadjuvant chemotherapy, treatment sequence and decision on possible simultaneous resection should be based on response evaluation. Whether or not neoadjuvant chemotherapy is beneficial is beyond the scope of this article. There is evidence that perioperative chemotherapy increases disease-free survival for patients aged $<75$ years and with $\leq 4$ liver metastases. [37].

\section{KNOWLEDGE GAPS}

Based on the literature reviewed above, there are still several unanswered questions concerning simultaneous resection. With respect to simultaneous resection, no randomized trials have investigated (i) the number of liver metastases that is considered safe to resect, (ii) the number of liver resections or liver segments that is considered safe to resect, (iii) the size of the future liver remnant that is considered safe, (iv) the timing of staged resection (liver or primary tumour first), (v) whether chemotherapy 
should be administered before or after surgery, (vi) oncological endpoints, (vii) quality of life or (viii) health economics. The lesson learned from current evidence is that these matters have to be addressed in well-planned multicentre randomized trials focusing on some of the abovementioned questions and thereby filling the knowledge gaps in order to recommend simultaneous surgery to the appropriate patients.

\section{CONCLUSION}

The concept of simultaneous resection of colorectal cancer with limited-disease liver metastases is appealing, with several potential benefits for both patients and health care systems. Despite this, high-level evidence is lacking, and an inherent reluctance exists due to the perceived risk of accumulating complications. We propose a pragmatic approach, consisting of the following:

- Stringent selection criteria in order to avoid major morbidity and mortality

- Adherence to surgical experience and preference regarding technique

- Accepting simultaneous resections for patients with good performance status and a limited liver tumour burden

- Avoiding simultaneous resections when requiring major hepatectomy and major colorectal resection

- Discussions and strategies through a multidisciplinary team meeting

A liver-first strategy in the setting of simultaneous resection is reasonable. High-quality trials are much needed to evaluate the role of systemic therapy, oncological outcomes, and both patient and health care system implications for these types of resections.

\section{ACKNOWLEDGEMENTS}

The authors wish to thank Dr. Kristoffer Watten Brudvik for valuable input to this manuscript.
Funding. No funding or sponsorship was received for this study or publication of this article.

Authorship. All named authors meet the International Committee of Medical Journal Editors (ICMJE) criteria for authorship for this article, take responsibility for the integrity of the work as a whole, and have given their approval for this version to be published.

Disclosures. The authors (Dyre Kleive, Eline Aas, Jon-Helge Angelsen, Erling A Bringeland, Arild Nesbakken, Linn S Nymo, Johannes K Schultz, Kjetil Søreide, and Sheraz Yaqub) have nothing to disclose.

Compliance with Ethics Guidelines. This article is based on previously conducted studies and does not contain any new studies with human participants or animals performed by any of the authors.

Data Availability. Data sharing is not applicable to this article, as no data sets were generated or analysed during the current study.

Open Access. This article is licensed under a Creative Commons Attribution-NonCommercial 4.0 International License, which permits any non-commercial use, sharing, adaptation, distribution and reproduction in any medium or format, as long as you give appropriate credit to the original author(s) and the source, provide a link to the Creative Commons licence, and indicate if changes were made. The images or other third party material in this article are included in the article's Creative Commons licence, unless indicated otherwise in a credit line to the material. If material is not included in the article's Creative Commons licence and your intended use is not permitted by statutory regulation or exceeds the permitted use, you will need to obtain permission directly from the copyright holder. To view a copy of this licence, visit http://creativecommons.org/licenses/bync/4.0/. 


\section{REFERENCES}

1. Jones TJ, Murphy AE, Tameron A, Hussain LR, Grannan K, Guend H, et al. Trends and outcomes of synchronous resection of colorectal metastasis in the modern era-analysis of targeted hepatic NSQIP database. J Surg Res. 2019;238:35-40.

2. Snyder RA, Hao S, Irish W, Zervos EE, Tuttle-Newhall JE, Parikh AA. Thirty-day morbidity after simultaneous resection of colorectal cancer and colorectal liver metastasis: american college of surgeons NSQIP analysis. J Am Coll Surg. 2020;230(4): 617-27.e9.

3. Kelly ME, Spolverato G, Lê GN, Mavros MN, Doyle F, Pawlik TM, et al. Synchronous colorectal liver metastasis: a network meta-analysis review comparing classical, combined, and liver-first surgical strategies. J Surg Oncol. 2015;111(3):341-51.

4. Vallance AE, van der Meulen J, Kuryba A, Charman SC, Botterill ID, Prasad KR, et al. The timing of liver resection in patients with colorectal cancer and synchronous liver metastases: a population-based study of current practice and survival. Colorectal Dis. 2018;20(6):486-95.

5. Baltatzis M, Chan AK, Jegatheeswaran S, Mason JM, Siriwardena AK. Colorectal cancer with synchronous hepatic metastases: systematic review of reports comparing synchronous surgery with sequential bowel-first or liver-first approaches. Euro J Surg Oncol. 2016;42(2):159-65.

6. Feng $\mathrm{Q}$, Wei $\mathrm{Y}$, Zhu $\mathrm{D}$, Ye $\mathrm{L}$, Lin $\mathrm{Q}, \mathrm{Li} \mathrm{W}$, et al. Timing of hepatectomy for resectable synchronous colorectal liver metastases: for whom simultaneous resection is more suitable-a meta-analysis. PLoS ONE. 2014;9(8):e104348.

7. Gavriilidis P, Sutcliffe RP, Hodson J, Marudanayagam R, Isaac J, Azoulay D, et al. Simultaneous versus delayed hepatectomy for synchronous colorectal liver metastases: a systematic review and meta-analysis. HPB. 2018;20(1):11-9.

8. Hillingsø JG, Wille-Jørgensen P. Staged or simultaneous resection of synchronous liver metastases from colorectal cancer-a systematic review. Colorectal Dis. 2009;11(1):3-10.

9. Slesser AA, Simillis C, Goldin R, Brown G, Mudan S, Tekkis PP. A meta-analysis comparing simultaneous versus delayed resections in patients with synchronous colorectal liver metastases. Surg Oncol. 2013;22(1):36-47.

10. Yin Z, Liu C, Chen Y, Bai Y, Shang C, Yin R, et al. Timing of hepatectomy in resectable synchronous colorectal liver metastases (SCRLM): simultaneous or delayed? Hepatology (Baltimore, MD). 2013;57(6):2346-57.

11. De Raffele E, Mirarchi M, Cuicchi D, Lecce F, Casadei R, Ricci C, et al. Simultaneous colorectal and parenchymal-sparing liver resection for advanced colorectal carcinoma with synchronous liver metastases: between conventional and miniinvasive approaches. World J Gastroenterol. 2020;26(42):6529-55.

12. Brouquet A, Mortenson MM, Vauthey JN, Rodriguez-Bigas MA, Overman MJ, Chang GJ, et al. Surgical strategies for synchronous colorectal liver metastases in 156 consecutive patients: classic, combined or reverse strategy? J Am Coll Surg. 2010;210(6):934-41.

13. Sturesson C, Valdimarsson VT, Blomstrand E, Eriksson S, Nilsson JH, Syk I, et al. Liver-first strategy for synchronous colorectal liver metastases-an intention-to-treat analysis. HPB. 2017;19(1):52-8.

14. Welsh FK, Chandrakumaran K, John TG, Cresswell $\mathrm{AB}$, Rees M. Propensity score-matched outcomes analysis of the liver-first approach for synchronous colorectal liver metastases. Br J Surg. 2016;103(5): 600-6.

15. Boudjema K, Locher C, Sabbagh C, Ortega-Deballon P, Heyd B, Bachellier P, et al. Simultaneous versus delayed resection for initially resectable synchronous colorectal cancer liver metastases: a prospective, open-label, randomized. Controlled Trial Ann Surg. 2021;273(1):49-56.

16. Huiskens J, Bolhuis $\mathrm{K}$, Engelbrecht MR, De Jong KP, Kazemier G, Liem MS, et al. Outcomes of resectability assessment of the Dutch colorectal cancer group liver metastases expert panel. J Am Coll Surg. 2019;229(6):523-32.e2.

17. Sandström P, Røsok BI, Sparrelid E, Larsen PN, Larsson AL, Lindell G, et al. ALPPS improves resectability compared with conventional two-stage hepatectomy in patients with advanced colorectal liver metastasis: results from a Scandinavian multicenter randomized controlled trial (LIGRO Trial). Ann Surg. 2018;267(5):833-40.

18. Dorcaratto D, Mazzinari G, Fernandez M, Muñoz E, Garcés-Albir M, Ortega J, et al. Impact of postoperative complications on survival and recurrence after resection of colorectal liver metastases: systematic review and meta-analysis. Ann Surg. 2019;270(6): 1018-27.

19. Driedger MR, Yamashita TS, Starlinger P, Mathis KL, Smoot RL, Cleary SP, et al. Synchronous resection of colorectal cancer primary and liver metastases: an outcomes analysis. HPB. 2021. 
20. Spampinato MG, Mandalá L, Quarta G, Del Medico P, Baldazzi G. One-stage, totally laparoscopic major hepatectomy and colectomy for colorectal neoplasm with synchronous liver metastasis: safety, feasibility and short-term outcome. Surgery. 2013;153(6):861-5.

21. Adam R, de Gramont A, Figueras J, Kokudo N, Kunstlinger F, Loyer E, et al. Managing synchronous liver metastases from colorectal cancer: a multidisciplinary international consensus. Cancer Treat Rev. 2015;41(9):729-41.

22. Shubert CR, Habermann EB, Bergquist JR, Thiels CA, Thomsen KM, Kremers WK, et al. A NSQIP review of major morbidity and mortality of synchronous liver resection for colorectal metastasis stratified by extent of liver resection and type of colorectal resection. J Gastrointestinal Surg. 2015;19(11):1982-94.

23. Griffiths C, Bogach J, Simunovic M, Parpia S, Ruo L, Hallet J, et al. Simultaneous resection of colorectal cancer with synchronous liver metastases; a practice survey. HPB. 2020;22(5):728-34.

24. Boeckx N, Koukakis R, Op de Beeck K, Rolfo C, Van Camp G, Siena S, et al. Primary tumor sidedness has an impact on prognosis and treatment outcome in metastatic colorectal cancer: results from two randomized first-line panitumumab studies. Ann Oncol. 2017;28(8):1862-8.

25. Brudvik KW, Jones RP, Giuliante F, Shindoh J, Passot $\mathrm{G}$, Chung $\mathrm{MH}$, et al. RAS mutation clinical risk score to predict survival after resection of colorectal liver metastases. Ann Surg. 2019;269(1):120-6.

26. Fong Y, Fortner J, Sun RL, Brennan MF, Blumgart LH. Clinical score for predicting recurrence after hepatic resection for metastatic colorectal cancer: analysis of 1001 consecutive cases. Ann Surg. 1999;230(3):309-18; discussion 18-21.

27. Ooki A, Akagi K, Yatsuoka T, Asayama M, Hara H, Nishimura Y, et al. Lymph node ratio as a risk factor for recurrence after adjuvant chemotherapy in stage III colorectal cancer. J Gastrointestinal Surg. 2017;21(5):867-78.

28. Ahmad A, Reha J, Saied A, Espat NJ, Somasundar P, Katz SC. Association of primary tumor lymph node ratio with burden of liver metastases and survival in stage IV colorectal cancer. Hepatobiliary Surg Nutr. 2017;6(3):154-61.
29. van Amerongen MJ, van der Stok EP, Fütterer JJ, Jenniskens SF, Moelker A, Grünhagen DJ, et al. Short term and long term results of patients with colorectal liver metastases undergoing surgery with or without radiofrequency ablation. Euro J Surg Oncol. 2016;42(4):523-30.

30. https://www.nccn.org/professionals/physician_gls/ default.aspx\#site.colon.pdf. Accessed 21.02.21

31. Bosker RJI, Van't Riet E, de Noo M, Vermaas M, Karsten TM, Pierie JP. Minimally invasive versus open approach for right-sided colectomy: a study in 12,006 patients from the Dutch surgical colorectal audit. Dig Surg. 2019;36(1):27-32.

32. Fretland ÅA, Dagenborg VJ, Bjørnelv GMW, Kazaryan AM, Kristiansen R, Fagerland MW, et al. Laparoscopic versus open resection for colorectal liver metastases: the OSLO-COMET randomized controlled trial. Ann Surg. 2018;267(2):199-207.

33. Aghayan DL, Kazaryan AM, Dagenborg VJ, Røsok BI, Fagerland MW, Bjørnelv GMW, et al. Long-term oncologic outcomes after laparoscopic versus open resection for colorectal liver metastases : a randomized trial. Ann Int Med. 2020.

34. Feinberg AE, Chesney TR, Acuna SA, Sammour T, Quereshy FA. Oncologic outcomes following laparoscopic versus open resection of pT4 colon cancer: a systematic review and meta-analysis. Dis Colon Rectum. 2017;60(1):116-25.

35. Olthof PB, Elfrink AKE, Marra E, Belt EJT, van den Boezem PB, Bosscha $\mathrm{K}$, et al. Volume-outcome relationship of liver surgery: a nationwide analysis. Br J Surg. 2020;107(7):917-26.

36. Huo YR, Phan K, Morris DL, Liauw W. Systematic review and a meta-analysis of hospital and surgeon volume/outcome relationships in colorectal cancer surgery. J Gastrointestinal Oncol. 2017;8(3):534-46.

37. Nordlinger B, Sorbye H, Glimelius B, Poston GJ, Schlag PM, Rougier $\mathrm{P}$, et al. Perioperative chemotherapy with FOLFOX4 and surgery versus surgery alone for resectable liver metastases from colorectal cancer (EORTC Intergroup trial 40983): a randomised controlled trial. Lancet (London, England). 2008;371(9617):1007-16. 